\title{
A bottom-up methodology to estimate vehicle emissions for the Beijing urban area
}

\author{
Haikun Wang ${ }^{a}$, Lixin $\mathrm{Fu}^{a, *}$, Xin $\operatorname{Lin}^{a}$, Yu Zhou ${ }^{a}$, Jinchuan $\mathrm{Chen}^{b}$ \\ ${ }^{a}$ Department of Environmental Science and Engineering, Tsinghua University, Beijing 100084, PR China \\ ${ }^{\mathrm{b}}$ Beijing Transportation Research Center, Beijing 100055, PR China
}

\section{A R T I C L E D A T A}

Article history:

Received 10 July 2008

Received in revised form

23 October 2008

Accepted 9 November 2008

Available online 13 December 2008

Keywords:

Vehicle missions

Air quality

Grid-based

Traffic data

Beijing

\begin{abstract}
A B S T R A C T
Vehicle exhaust emissions have posed a serious threat in recent years to the urban air quality of Beijing. It is necessary to accurately estimate the magnitude and distribution of these emissions in order to reduce the uncertainty of local scale air quality modeling assessment. This paper provides a bottom-up approach by combining vehicle emission factors and vehicle activity data from a travel demand model estimated at the grid level to generate vehicle emissions data for the Beijing urban area in 2005. In that year, vehicular emissions of HC, CO and NOx were respectively $13.33 \times 10^{4}, 100.02 \times 10^{4}$ and $7.55 \times 10^{4}$ tons. The grid-based emissions were also compared with the vehicular emission inventory developed by macro-scale approach. It shows this bottom-up approach can result in better estimates of the levels and spatial distribution of vehicle emissions than the macro-scale method that relies on more average and aggregated information.
\end{abstract}

(c) 2008 Elsevier B.V. All rights reserved.

\section{Introduction}

Vehicle emission inventory for regional or national scale are usually developed using a macro-scale (or top-down) approach in China. For these applications, emission factors are assumed to represent long-term vehicle population averages for a given vehicle class, and are often based on default or average inputs. Average vehicle activity data, such as Vehicle Kilometers Traveled (VKT), are estimated by investigation and/or a statistical method for each fleet. The emissions inventory is estimated as the product of emission factors and vehicle activity. Then, some spatial surrogates, such as population and road density, are used to allocate macro-scale emissions to grid cells as required by the air quality model (Cook et al., 2006; Hao et al., 2000; He, 1999).

However, there exist some limitations of this approach. The same emission factors for each vehicle fleet under average speed, or emissions allocated using the spatial surrogates from a larger geographic scale, may not reflect the real vehicle emission conditions at local scales. Thus, topdown inventories, which are practical for national scale applications, may mischaracterize emissions at the individual county or sub-county. A study conducted in Minneapolis-St. Paul, Minnesota, which used spatial surrogates to allocate mobile source emissions to census tracts, found that the dispersion model tended to over predict at low monitored concentrations, and under predict at levels of high monitored concentrations (Pratt et al., 2004). Cook et al. (2006) also found that estimation for individual road links to develop an emission inventory results in a much different spatial distribution of emissions than applying top-down methodology.

More accurate vehicle emission inventory can be developed using a bottom-up approach that relies on using more detailed emission factors and vehicle activity data from a travel demand model (TDM). TDM used for transportation planning can provide more detailed information on the spatial distribution of roadway types, vehicle activity, and speeds

\footnotetext{
* Corresponding author. Tel./fax: +861062771465.

E-mail address: fuchen@mail.tsinghua.edu.cn (L. Fu).
} 
along those roads. These data may be used with the emission factors from the vehicle emission model to create more detailed, spatially distributed emission rates at the local level, thus providing better estimates of the distributions of pollutants concentration in a city (Kinnee et al., 2004; Cohen et al., 2005).

Beijing, the capital and also the center of policy and culture in China, has an urban area of about $1000 \mathrm{~km}^{2}$ and a population more than 14 million. The road system in Beijing can be described as a network with ring roads and radial roads as its arteries. The road around the Forbidden City is called the first ring, and the ring roads beyond are the $2 \mathrm{nd}$, 3rd, 4th, 5th and 6 th ring roads in order of the radial distance from center of the city. In this study, we focus on the vehicle emissions within the 6th ring road which is described as the Beijing urban area. The total vehicle population of Beijing has almost tripled during the last decade reaching more than 2 million by the end of 2005 (BSB, 2006). Mobile sources have also been identified as the most important air pollution contributor in this metropolis (Hao and Wang, 2005).

In this study, the grid-based vehicle emission inventory for Beijing urban area will be established using a bottom-up approach. The vehicle activity data from travel demand modeling were used in conjunction with emission factors from the MOBILE5B-China model to develop the grid-based emission inventory. The results were then compared with the vehicular emission inventory developed by the macro-scale method to analyze their uncertainties.

\section{Methodologies}

\subsection{Modeling approach}

The modeling procedure in this study consists of three consecutive steps that are shown in Fig. 1.

TransCAD (Caliper Corporation, 2006), one of the most popular and capable transportation planning software, is applied here to estimate the traffic flow and speed in each grid for the Beijing urban area. It may also be interfaced with pollutant emissions/dispersion models to simulate the effect

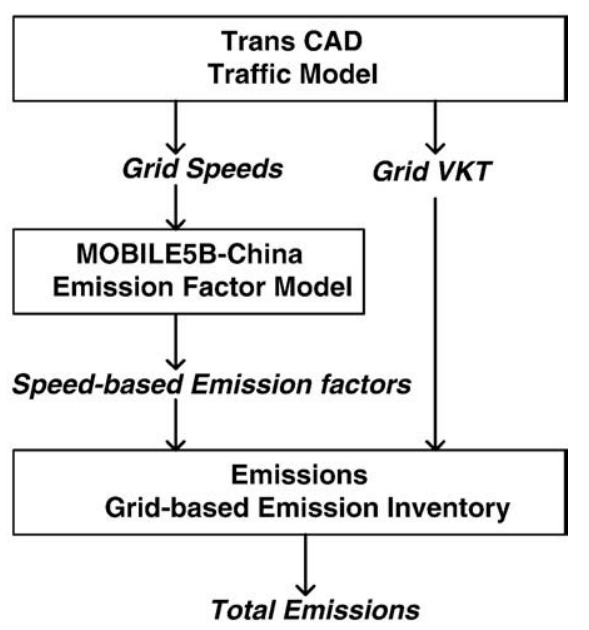

Fig. 1-Modeling approach. of changes in land use, roadway network, and transportation policy on emission estimates.

MOBILE5B, developed by the US Environmental Protection Agency (1994), uses average speed, vehicle fleet characteristics, ambient condition, and other parameters to estimate emission factors. In this study, grid vehicular speeds are used to obtain emission factors for each vehicle type in each grid. Grid VKT is multiplied by the corresponding grid emission factors and summed over all grids to obtain total emissions (Eq. (1)). This approach is physically representative of realistic traffic conditions in each grid cell of the city. Nevertheless, current practice favors applying the macro-scale approach (Eq. (2)) to develop the vehicle emission inventory for the cities in China.

$$
\begin{aligned}
& \mathrm{Q}^{P}=\sum_{i=1}^{m} \sum_{j=1}^{n} E F_{i, j}^{P} \times \mathrm{VMT}_{i, j} \\
& \mathrm{Q}^{P}=\sum_{i=1}^{m} E F_{i, \text { average }}^{P} \times \mathrm{VMT}_{i}
\end{aligned}
$$

Where, $Q^{P}$ is the total emissions for pollutant $P, g ; E F_{i, j}^{P}$ is the emission factor of pollutant $P$ for vehicle type $i$ in grid cell $j, \mathrm{~g} / \mathrm{km} ; E_{i, \text { average }}^{P}$ is the average emission factor of pollutant $P$ for vehicle type $\mathrm{i}, \mathrm{g} / \mathrm{km} ; V_{K T}$ i, is the vehicle kilometers traveled for vehicle type $i$ in grid cell $j, \mathrm{~km}$; and $V_{K T} i$ is the total vehicle kilometers traveled for vehicle type $i, \mathrm{~km}$.

\subsection{Vehicle emission factors}

Vehicle emission factors depend on many considerations, which can be grouped as vehicle emission control level; vehicle type and fuel type; utilization parameters such as age, accumulated mileage, inspection and maintenance; operating modes like average speed, fraction of cold/hot starts, air conditioning; and ambient parameters such as temperature and humidity. In this research, modified MOBILE5B (MOBILE5B-China) was used to estimate vehicle emission factors under different speeds. Researchers at Tsinghua University have adopted MOBILE5B-China model to estimate vehicle emissions in their studies over the past 10 years (Fu et al., 1997; Hao et al., 2000, 2001, 2002, 2006; He et al., 1998). Information and internal functions specific to Beijing were substituted for many of the functions in MOBILE5B-China in recent years. Furthermore, with the help of the on-road vehicle emissions measurement using PEMS in Beijing (Hu et al., 2004), speed-emission factor coefficients of Beijing are updated in MOBILE5B-China. This allows it to reflect the effect of driving patterns in Beijing on the emission factors. A detailed description of the study modifying and applying MOBILE5BChina to estimate vehicle emission factors in Beijing can be found in the literature (He, 1999; Hao et al., 2000).

In this study, the vehicles driving in the urban area of Beijing were summarized into 6 classes: passenger car (PC), shuttle bus (SB), taxi, heavy duty truck (HDT), light duty truck (LDT) and bus. The variation of emission factors of HC, CO and NOx with speed (up to $80 \mathrm{~km} / \mathrm{h}$ ) for each vehicle class are calculated with MOBILE5B-China and shown in Fig. 2. It shows that $\mathrm{HC}$ and $\mathrm{CO}$ emission factors have a strong relationship with speed and generally decrease with increasing speeds, 
(a)

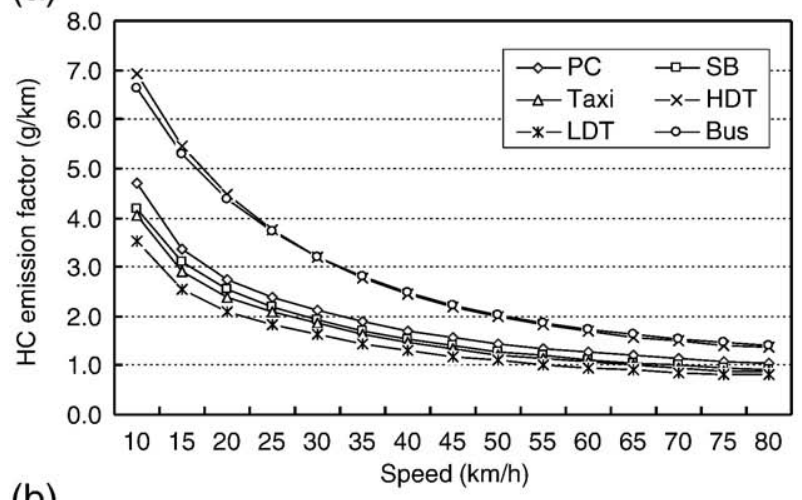

(b)

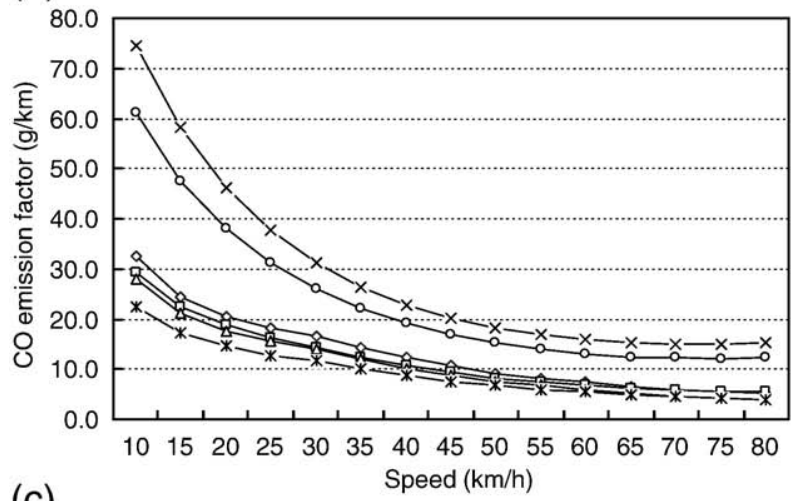

(c)

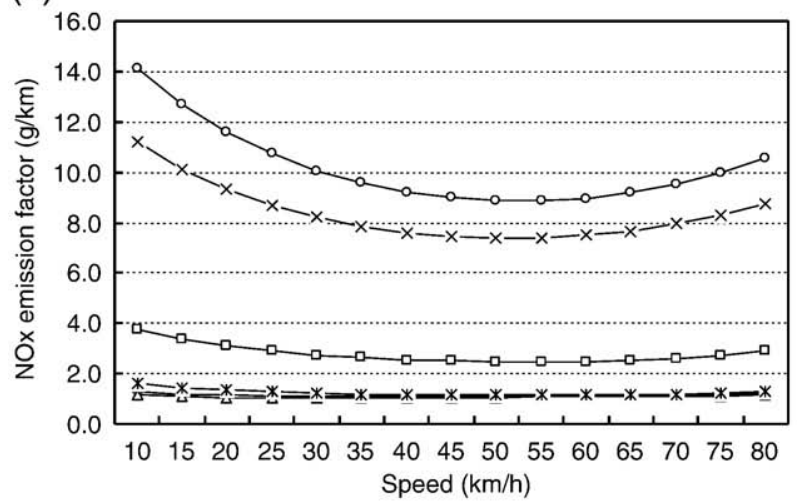

Fig. 2-Variation of emission factors with speed: (a) HC, (b) CO, and (c) NOx.

rapidly at first then more slowly. The NOx emission factors, which are less sensitive to speed changes, follow a parabolic path and tend to decrease to $50 \mathrm{~km} / \mathrm{h}$ and then increase.

\subsection{Vehicle activity and spatial distributions}

The geographic vehicle activities were estimated by the Beijing Transportation Research Centre with TransCAD model and traffic investigations. The urban area of Beijing was divided into $20381 \mathrm{~km} \times 1 \mathrm{~km}$ grid cells according to the road distributions. Information provided in each grid cell includes geographic coordinates; road length; average daily traffic flow, speed and VKT for each vehicle type. The VKT distributions of each vehicle type in various speed bins are presented in Table 1. It shows that a significant proportion of total VKT are located in the speed bins between 20 to $40 \mathrm{~km} / \mathrm{h}$ in Beijing urban area.

\section{Result and discussion}

\subsection{Grid-based emission inventory}

When the vehicle activity and speed correlated emission factors are acquired, the grid-based emission inventory can be developed according to Eq. (1). The grid-based vehicle emission inventories of $\mathrm{HC}, \mathrm{CO}$ and $\mathrm{NOx}$ for the Beijing urban area in 2005 are shown in Figs. 3-5, respectively.

The figures show that the distribution of vehicle emissions in Beijing's urban area is not uniform and the emissions are greater in urban core as compared to surrounding areas. This is due to the following reasons: (1) greater traffic flow and vehicle density in the urban center; (2) a road system that is overburdened causing vehicles to operate under difficult conditions of low speed and frequent acceleration, deceleration and idle, that leads to high emission rates of the pollutants. The radial roads with heavy traffic across some grids outside the urban core area also contribute to high emission rates in these grids.

Grid-based emissions may be aggregated to calculate the total vehicular emissions. This shows that vehicular emissions of $\mathrm{HC}, \mathrm{CO}$ and $\mathrm{NOx}$ are respectively $13.33 \times 10^{4}$, $100.02 \times 10^{4}$ and $7.55 \times 10^{4}$ tons for Beijing urban area in 2005 .

\subsection{Impact of vehicle activity on emission estimations}

For the macro-scale approach, the average network speed is used to calculate an average emission factor for the whole city in China. The VKT of various vehicle types are usually acquired through field survey (e.g. parking lot survey and questionnaire survey). Total emissions are then estimated by multiplying total VKT by the average emission factor. Lin

Table 1 - VKT distributions of each vehicle class in various speed bins

\begin{tabular}{lrrrrrr}
$\begin{array}{l}\text { Speed bins } \\
(\mathrm{km} / \mathrm{h})\end{array}$ & PC & SB & Taxi & HDT & LDT & Bus \\
\hline$[0,5)$ & $0.00 \%$ & $0.00 \%$ & $0.00 \%$ & $0.00 \%$ & $0.00 \%$ & $0.64 \%$ \\
{$[5,10)$} & $0.35 \%$ & $0.29 \%$ & $0.28 \%$ & $0.72 \%$ & $0.72 \%$ & $0.55 \%$ \\
{$[10,15)$} & $1.43 \%$ & $1.11 \%$ & $1.51 \%$ & $2.66 \%$ & $2.64 \%$ & $2.73 \%$ \\
{$[15,20)$} & $5.47 \%$ & $3.89 \%$ & $5.15 \%$ & $8.32 \%$ & $8.25 \%$ & $8.85 \%$ \\
{$[20,25)$} & $14.72 \%$ & $11.94 \%$ & $14.05 \%$ & $18.47 \%$ & $18.43 \%$ & $20.37 \%$ \\
{$[25,30)$} & $23.51 \%$ & $20.38 \%$ & $23.73 \%$ & $27.69 \%$ & $27.64 \%$ & $27.62 \%$ \\
{$[30,35)$} & $16.88 \%$ & $15.77 \%$ & $17.55 \%$ & $18.64 \%$ & $18.55 \%$ & $17.69 \%$ \\
{$[35,40)$} & $8.18 \%$ & $9.54 \%$ & $8.17 \%$ & $7.95 \%$ & $7.97 \%$ & $6.14 \%$ \\
{$[40,45)$} & $4.17 \%$ & $4.68 \%$ & $4.88 \%$ & $3.72 \%$ & $3.69 \%$ & $4.00 \%$ \\
{$[45,50)$} & $4.24 \%$ & $4.46 \%$ & $5.73 \%$ & $3.56 \%$ & $3.54 \%$ & $3.17 \%$ \\
{$[50,55)$} & $3.74 \%$ & $4.28 \%$ & $3.83 \%$ & $2.00 \%$ & $1.98 \%$ & $2.27 \%$ \\
{$[55,60)$} & $5.02 \%$ & $5.94 \%$ & $4.27 \%$ & $1.71 \%$ & $1.69 \%$ & $3.19 \%$ \\
{$[60,65)$} & $1.95 \%$ & $2.73 \%$ & $1.75 \%$ & $0.68 \%$ & $0.71 \%$ & $0.87 \%$ \\
{$[65,70)$} & $1.40 \%$ & $1.99 \%$ & $1.21 \%$ & $1.17 \%$ & $1.18 \%$ & $0.71 \%$ \\
{$[70,80)$} & $3.23 \%$ & $4.30 \%$ & $3.39 \%$ & $0.93 \%$ & $1.00 \%$ & $0.27 \%$ \\
{$[80,100)$} & $5.71 \%$ & $8.73 \%$ & $4.49 \%$ & $1.78 \%$ & $2.02 \%$ & $0.93 \%$ \\
\hline
\end{tabular}




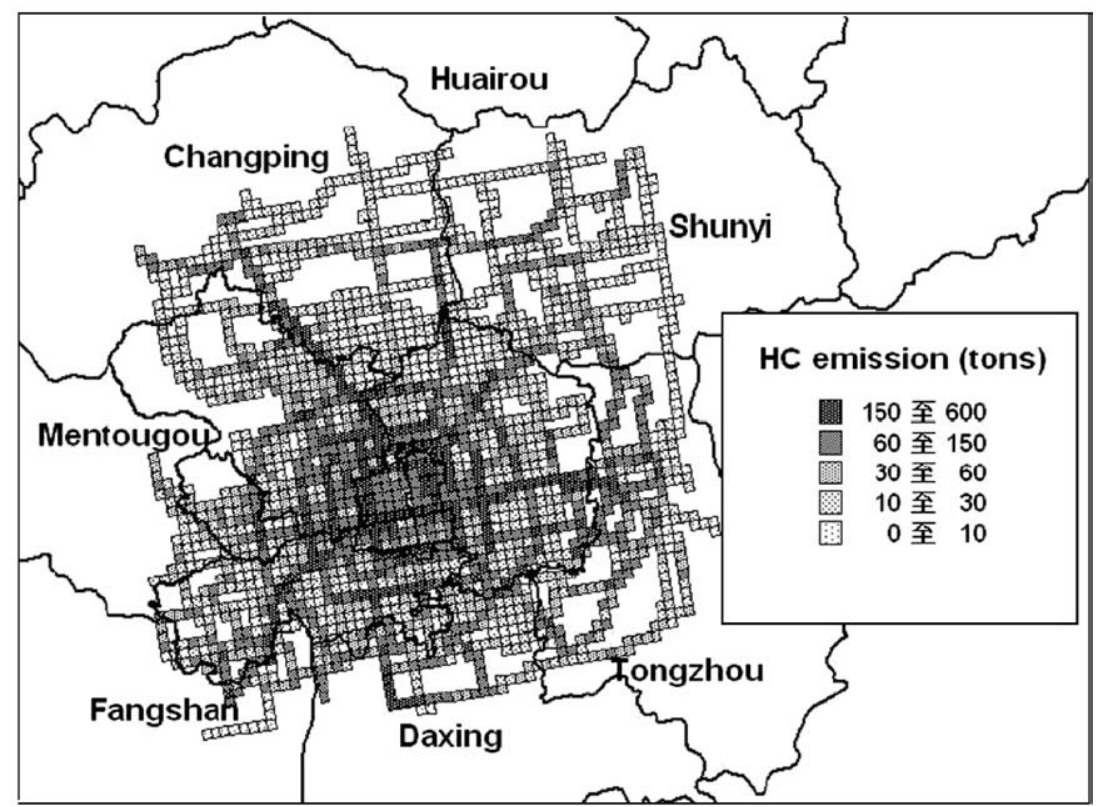

Fig. 3-Spatial distribution of vehicular HC emissions for Beijing urban area in 2005.

(2007) developed the vehicle emission inventories for Beijing in his thesis using this approach. The total stabilized running emissions for the Beijing urban area based on the two different methods are presented in Fig. 6 . It should be noted that the macro-scale emission inventory was developed for the whole area of Beijing (including the suburban area) in 2005. According to a study, vehicle emissions in the urban area made up 75\% (DESE, 2005) of the total air emissions in Beijing in 2002 for vehicle-related pollutants. Considering the suburbanization of Beijing in recent years, the vehicle activity in the suburban area likely increased. The study estimated that the vehiclerelated emissions in the suburbs were $70 \%$ of the total.
Fig. 6 shows that compared with grid-based (micro-scale) emission inventory macro-scale methodologies may underestimate emissions in Beijing by $18.7 \%$ and $6.1 \%$ of $\mathrm{HC}$ and CO emissions, respectively. There may be two reasons for this underestimation:

(1) The vehicle activity data used in the macro-scale method are usually from statistical material, which reflect the static level of average vehicle activity throughout the city. There may exist significant differences between these data and the actual vehicle activity level on the roads (Wang et al., 2008). The TDM model

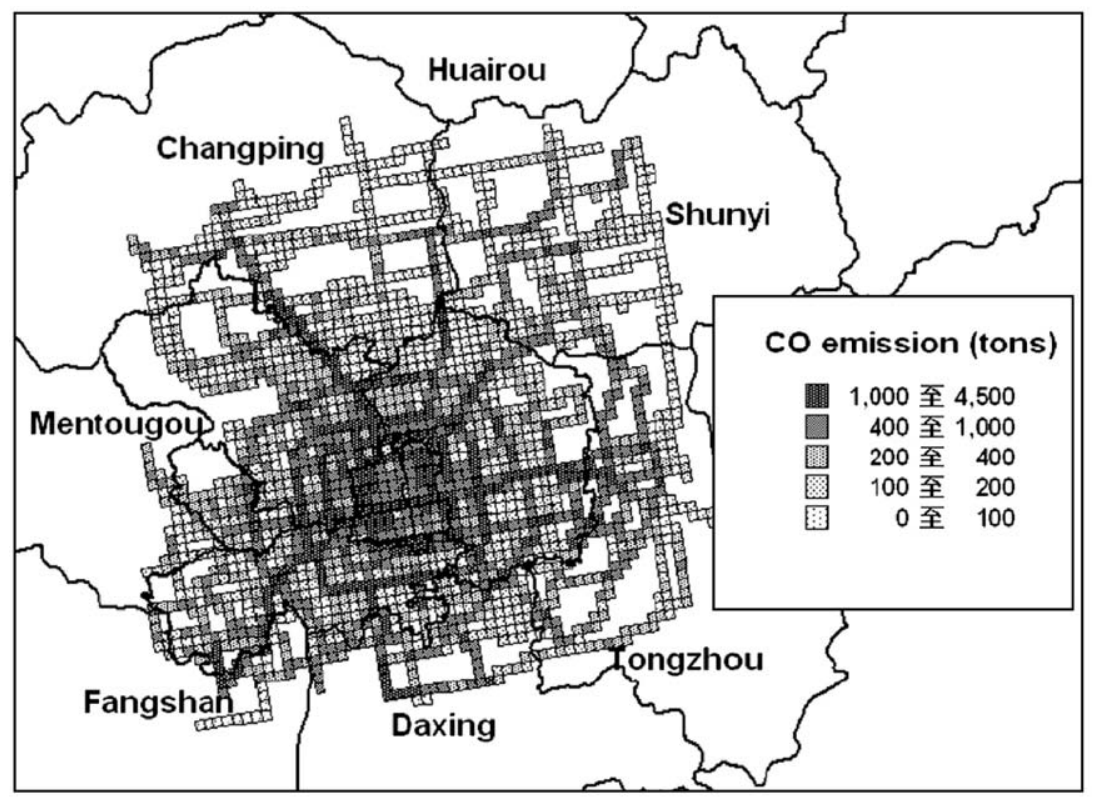

Fig. 4-Spatial distribution of vehicular CO emissions for Beijing urban area in 2005. 


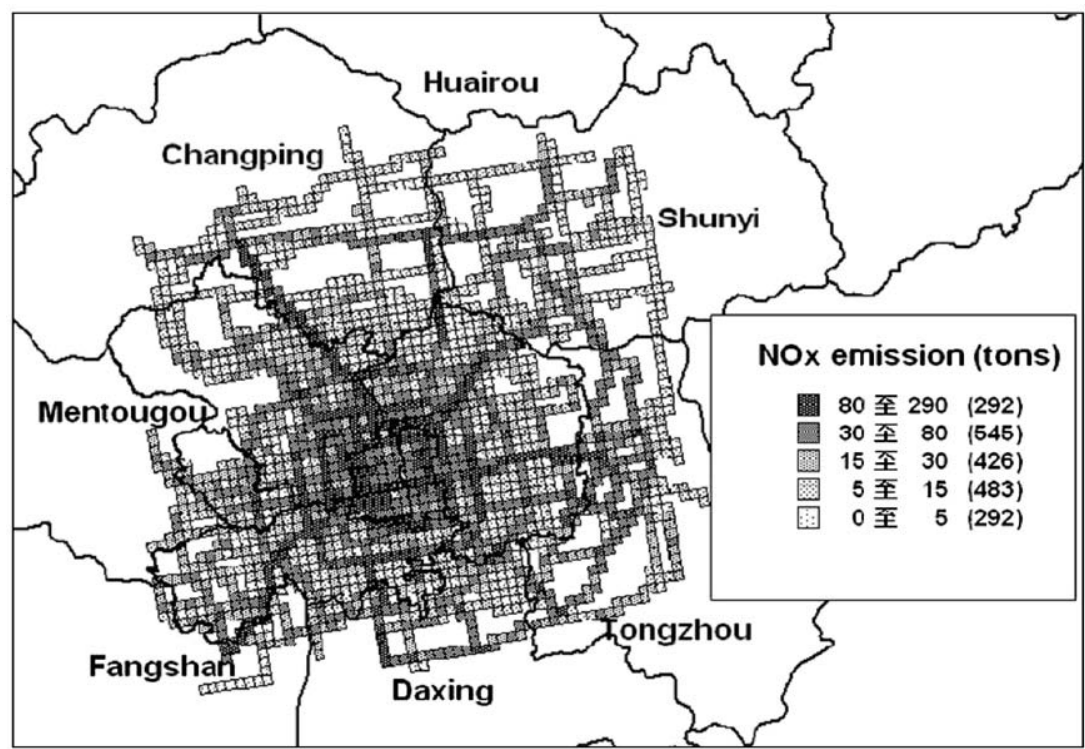

Fig. 5-Spatial distribution of vehicular NOx emissions for Beijing urban area in 2005.

and field investigation were applied in the grid-based method which reflects the actual vehicle activity on the roads. Table 2 illustrates that most of the activities of PCs and taxis occur in the downtown area and comprise over $90 \%$ of the total VKT in the urban area of Beijing. However, the macro-scale approach could not identify the spatial distributions of VKT accurately due to its intrinsic drawbacks. It underestimated by $8 \%$ and $63 \%$ the activity for PCs and taxies, respectively. Because the light duty vehicles (e.g. PCs and taxies) are the main sources of $\mathrm{HC}$ and $\mathrm{CO}$ emissions in the city, most of the vehicular $\mathrm{HC}$ and $\mathrm{CO}$ emissions are concentrated in the urban area of Beijing. Any differences between the macro-scale approach and vehicle actual activity may result in underestimating the vehicular $\mathrm{HC}$ and $\mathrm{CO}$ emissions in the urban area.

(2) Because of Beijing's importance in China, there are many non-local vehicles and military vehicles driving in the urban area. However, these kinds of vehicles are not

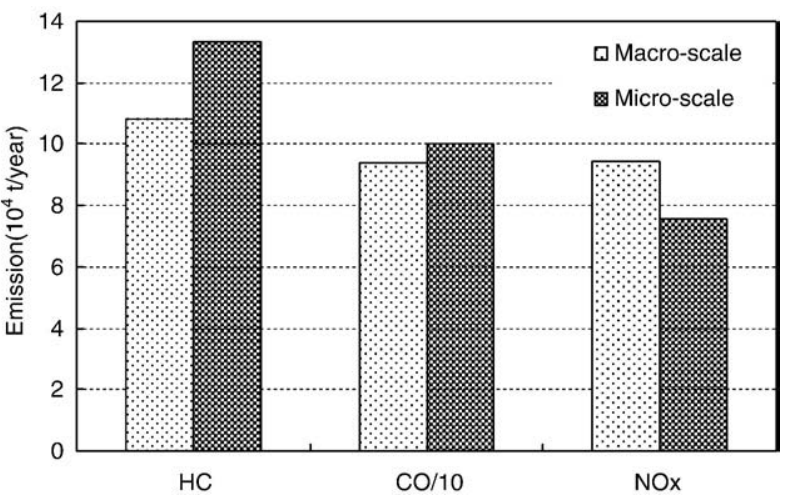

Fig. 6-Macro- and micro-scale vehicle emission inventories for Beijing urban area. included in the local statistical material. Since they are excluded from the vehicle emission inventories used in macro-scale methods, this could also lead to the underestimation of vehicular activity and emissions in the urban area of Beijing.

In Beijing, the HDT use is restricted in the urban area so most of their activities occur in the suburbs. This contributes to high vehicular NOx emissions in suburban Beijing. However, the macro-scale method ignores these different spatial distributions of vehicle activity for various fleets. Table 2 shows that, compared with the micro-scale approach, the macro-scale method will overestimate $51 \%$ and $211 \%$ of the vehicle activity for LDTs and HDTs, respectively. As trucks are the main source of NOx emission in the metropolitan cities in China (Wang et al., 2008), the macro-scale method appears to overestimate the NOx emissions in the urban area of Beijing (Fig. 6).

\subsection{Impact of emission factors on emission estimations}

When the VKT data is derived from the TDM model, it can be used for estimating emissions. Traditionally, the VKT data will be aggregated and multiplied by the average emission factor based on the average travel speed in the city to calculate the vehicle emissions (travel-based). In this study, the emission factors and VKT data are not simply connected at the aggregate level; instead, they interact according to different

Table 2-VKT for various vehicle types in macro- and micro-scale method, $10^{4} \mathrm{~km} /$ day

\begin{tabular}{lllllll} 
Vehicle type & PC & SB & Taxi & HDT & LDT & Bus \\
\hline Macro-scale & 11252 & 45 & 1285 & 1277 & 621 & 128 \\
Micro-scale & 12281 & 259 & 3472 & 411 & 413 & 252 \\
Percent difference & $-8 \%$ & $-83 \%$ & $-63 \%$ & $211 \%$ & $51 \%$ & $-49 \%$
\end{tabular}


Table 3 - Travel- and grid-based total running emissions for Beijing urban area

\begin{tabular}{llll} 
Pollutants & HC & CO & NOx \\
\hline Travel-based $\left(10^{4}\right.$ tons $)$ & 11.61 & 88.55 & 7.19 \\
Grid-based $\left(10^{4}\right.$ tons $)$ & 13.33 & 100.02 & 7.55 \\
Percent difference & $15 \%$ & $13 \%$ & $5 \%$ \\
\hline
\end{tabular}

speed values in each grid cell. In other words, grid VKT is aggregated and grid-based emission factors are assigned based on the grid average speeds estimated in travel demand models. The travel-based and grid-based vehicle emissions are presented in Table 3.

It shows that the grid-based method generally results in higher emissions than the travel-based method, and the percent difference of the emissions between these two methods are respectively 15\%, 13\% and 5\% for $\mathrm{HC}$, CO and NOx. Because the same total VKT were used in these two methods, the differences are mainly attributed to the different approaches of emission factor development. Therefore, we may underestimate the vehicle emissions in the Beijing urban area if the travel-based method is applied. Smit et al. (2008) also drew the similar conclusions in their study in Amsterdam, Netherlands.

Table 3 also shows that the NOx difference between these two methods is not as high as HC or CO. This is due to HC and $\mathrm{CO}$ emissions being more sensitive to the speed and driving mode than NOx, which can be seen in Fig. 2.

\section{Conclusions}

A bottom-up methodology using the TDM traffic model and MOBILE5B-China are applied to assess the traffic-induced emissions in the Beijing urban area in this study. The gridbased vehicular emissions of $\mathrm{HC}, \mathrm{CO}$ and NOx are calculated based on grid-based vehicle activities and emission factors, and they show clear spatial distributions. The total vehicle emissions of $\mathrm{HC}, \mathrm{CO}$ and $\mathrm{NOx}$ are respectively $13.33 \times 10^{4}$, $100.02 \times 10^{4}$ and $7.55 \times 10^{4}$ tons in Beijing urban area in 2005 .

The result of the macro-scale approach to determine vehicular activities and emissions has been compared with the micro-scale methodology. When compared to the relatively realistic grid-based approach, the macro-scale approach underestimated the VKT for PC, SB, taxi and bus. It also overestimated the activities of HDTs and LDTs in the Beijing urban area. The macro-scale approach provided acceptable deviations (-18.7 to $-6.1 \%)$ for both HC and CO emissions. However, it may overestimate NOx emissions since it does not consider the traffic restriction of HDTs in the Beijing urban area.

The comparison of travel- and grid-based emission inventory indicates that the emissions calculated by these two methods differ from each other even though they have the equal VKT. Because the current emission models generally have a relationship between emission factors and speeds (Fig. 2), when VKT and emission factors are combined, the grid-based approach is likely to be more sensitive in measuring emission effects due to specific changes in each grid, particularly those grids with low speeds (e.g., heavily congested area) and high speeds (e.g., the area with freeways).
The method of integrating the traffic model and vehicle emission model to estimate traffic emissions presented in this study can be extended in various ways. For example, it can be used to evaluate the impact of urban land plan on traffic emissions. It can also be used to evaluate the effect of traffic management measures on traffic emission reduction. Future research will be necessary to determine whether these types of evaluations will improve traffic emissions modeling.

\section{Acknowledgements}

This work was supported by the China National Nature Science Foundation (Project No. 50678092) and Beijing Environmental Protection Bureau. We also thank Mr. Chuck Freed formally of US. EPA for his aid in editing this paper. The contents of this paper are solely the responsibility of the authors and do not necessarily represent official views of the sponsors.

\section{R E F E R E N C E S}

BSB (Beijing Statistical Bureau). Beijing Statistical Yearbook 2006. Beijing, China: China Statistics Press; 2006 (in Chinese).

Caliper Corporation. TransCAD transportation GIS software. America: Caliper Corporation; 2006.

Cohen J, Cook R, Bailey C, Carr E. Relationship between motor vehicle emissions of hazardous air pollutants, roadway proximity, and ambient concentrations in Portland, Oregon. Environ Model Softw 2005;20:7-12.

Cook R, Touma JS, Beidler A, Strum M. Preparing highway emissions inventories for urban scale modeling: a case study in Philadelphia. Transp Res Part D Transp Environ 2006;11:396-407.

DESE (Department of Environmental Science and Engineering, Tsinghua University). Mobile source database, emission inventory and treatment proposal for Beijing, H030630540430. Beijing, China: Tsinghua University; 2005.

Fu L, He K, He D, Tang Z, Hao J. A study on models of MOBILE source emission factors. Acta Sci Circumstantiae 1997;17 (4):474-9 (in Chinese).

Hao J, Wang L. Improving urban air quality in China: Beijing case study. J Air Waste Manage Assoc 2005;55:1298-305.

Hao J, He D, Wu Y, Fu L, He K. A study of the emission and concentration distribution of vehicular pollutants in the urban area of Beijing. Atmos Environ 2000;34:453-65.

Hao J, Wu Y, Fu L, He K, He D. Motor vehicle source contributions to air pollutants in Beijing. Environ Sci 2001;22:1-6 (in Chinese).

Hao J, Wu Y, Fu L, He D, He K. Study of the urban vehicular emission control program system in China. J Appl Meteorol Sci 2002;13:195-203 (Suppl.), (in Chinese).

Hao J, Hu J, Fu L. Controlling vehicular emissions in Beijing during the last decade. Transp Res Part A Gen 2006;40:639-51.

He D, Study on urban vehicular pollution assessment system and emission control target. Ph. D. Dissertation. Beijing, China: Tsinghua University; 1999 (in Chinese).

He D, Hao J, He K, Fu L. Vehicle emission factors determination using model calculation. Environ Sci 1998;19(3):7-10 (in Chinese).

Hu J, Hao J, Fu L, Wu Y, Wang Z, Tang U. Study on on-board measurements and modeling of vehicular emissions. Environ Sci 2004;25(3):19-25 (in Chinese).

Kinnee E, Touma J, Mason R, Thurman J, Beidler A, Bailey C, et al. Allocation of on-road mobile emissions to road segments for 
air toxics modeling in an urban area. Transp Res Part D Transp Environ 2004;9:139-50.

Lin X, A study on the combination of top-down and bottom-up methodology for vehicle emissions inventory. Master Thesis. Beijing, China: Tsinghua University; 2007 (in Chinese).

Pratt G, Wu C, Bock D. Comparing air dispersion model predictions with measured concentrations of VOCs in urban areas. Environ Sci Technol 2004;38:423-30.

Smit R, Poelman M, Schrijver J. Improved road traffic emission inventories by adding mean speed distributions. Atmos Environ 2008;42:916-26.
US Environmental Protection Agency (US EPA). User's guide to MOBILES (Mobile Source Emission Factor Model); 1994. EPA-AA-TEB-94-01.

Wang H, Chen C, Huang C, Fu L. On-road vehicle emission inventory and its uncertainty analysis for Shanghai, China. Sci Total Environ 2008;398(1-3):60-7. 